\title{
Fine structure and distribution of antennal sensilla of stink bug Arma chinensis (Heteroptera: Pentatomidae)
}

\author{
Jian Zhang, Xiaojun Zhang, Chunyu Liu, Lipeng Meng \& Yulin Zhou*
}

Zhang, J., Zhang, X. J., Liu, C. Y., Meng, L. P. \& Zhou, Y. L. 2014: Fine structure and distribution of antennal sensilla of stink bug Arma chinensis (Heteroptera: Pentatomidae). — Entomol. Fennica 25: 186-198.

Scanning electron microscopy was used to examine the morphology, ultrastructure, and distribution of antennal sensilla of the stink bug Arma chinensis. Two types of sensilla trichodea (ST 1-2), four types of sensilla basiconica (SB 14 ), one type of sensilla chaetica ( $\mathrm{SCH}$ ), one type of sensilla cavity ( $\mathrm{SCA}$ ) and one type of sensilla coeloconica ( $\mathrm{SCO}$ ) were distinguished on the antennae in both sexes. ST1 and ST2 were absent from the scape and pedicel. SB1 were absent from the scape. SB2 were distributed throughout the antennae. SB3 were located on the second pedicel and the two flagellomeres. SB4 were absent from the second flagellomere. $\mathrm{SCH}$ was observed on the second pedicel and the two flagellomeres. SCA and SCO occurred only on the second flagellomere. SB1 clusters occurred on the distal part of the second flagellomere. We compared the morphology and structure of these sensilla to other Heteroptera and discuss their possible functions.

J. Zhang, X. J. Zhang \& L. P. Meng, Institute of Forest Protection, Jilin Provincial Academy of Forestry and Jilin Centre Station of Forestry Biological Control; Linhe St. 3528, Changchun, China 130033

C. Y. Liu, Engineering Research Center of Chinese Ministry of Education for Edible and Medicinal Fungi, Jilin Agricultural University, Xincheng St. 2888, Changchun, China, 130118

Y. L. Zhou, (*Corresponding author), College of Life Sciences, Jilin University, Qianjin St.2699, Changchun, China, 130012; E-mail:tracy5468@163.com

Received 3 March 2014, accepted 11 July 2014

\section{Introduction}

Arma chinensis (Fallou) (Heteroptera: Pentatomidae) is an important predaceous insect species that is widely distributed throughout eastern Asia. It is an important and a broadly-applied biological control agent of forest pests in China. They are usually found on elm and poplar, and in cotton and soybean fields (Xu et al. 1981, Song et al. 2010, Zou et al. 2012). They prey upon a large variety of species, and can effectively suppress agricultural and forest pests in the orders Lepidoptera, Coleoptera, Hymenoptera and Hemiptera (Xu et al. 1984, Zou et al.2013). Knowledge of the host location mechanism employed by this species would be useful for developing methods for applying them as biological control agents.

Abundant information is available on biological characteristic, predatory behavior, and artificial rearing of predaceous stink bugs (Streams et 
al. 1963, Zahn et al. 2008, De Bortoli et al. 2011, Helmey-Hartman \& Miller 2014). Mechanisms underlining mate location and recognition are still unknown for most stink bugs. Research on stink bug mating behavior has indicated the importance of antennae in mate location and recognition. Numerous studies have characterized antennal sensilla of various insects (Zacharuk 1980, Keil \& Steinbrecht 1984, Städler 1984, Cônsoli et al. 1999, Bleeker et al. 2004, Bourdais et al. 2006, Yu et al. 2013) whereas very few of such studies have focused on Pentatomidae (Rani \& Madhavendra 1995, Brézot et al. 1997, Silva et al. 2010).

Insect antennae play important roles in various behaviors, including habitat searching, host location, discrimination, courtship and mating behavior (Schneider 1964). Antennae of insects contain sensory sensilla, which function in the detection of various stimuli involved in the host habitat and mate location (Chapman 1998). As part of our ongoing research on mate and host location mechanisms of $A$. chinensis, we characterized and determined the abundance and distribution of the antennal sensilla of this stink bug using the techniques of scanning electron microscopy (SEM). This work is a prerequisite for future electrophysiological studies of the antennal sensory system involved in intraspecific chemical communication. The types of sensilla of $\mathrm{A}$. chinensis are also compared with those described for other heteropteran insects (e.g., Rani \& Madhavendra 1995, Brézot et al. 1997, Chinta et al. 1997, Rani \& Madhavendra 2005, Silva et al. 2010).

\section{Material and methods}

The morphology and distribution of sensilla on the antennae of $A$. chinensis were investigated. Sensilla on the dorsal and ventral surfaces of the antennae of both sexes were identified, counted, and measured. To characterize the sensilla we used the nomenclature proposed by Schneider (1964) and Zacharuk (1980, 1985). The following abbreviations are used for different types of sensilla:

ST1: Sensilla trichoidea 1, ST2: Sensilla trichoidea 2, SB1: Sensilla basiconica 1, SB2:
Sensilla basiconica 2, SB3: Sensilla basiconica 3, SB4: Sensilla basiconica 4, SCH: Sensilla chaetica, SCA: Sensilla cavity, SCO: Sensilla coeloconic.

\subsection{Insects}

Adults of $A$. chinensis were initially collected from Ulmus macrocarpa Hance trees, located in Qian'an County, Jilin Province, northeastern China, and subsequently maintained in the laboratory for several generations. Arma chinensis were fed with Chinese oak silk moth, Antheraea pernyi, pupae and reared at $27 \pm 1^{\circ} \mathrm{C}, \mathrm{RH}$ of $75 \pm$ $5 \%$, and a 16:8 (L:D) hour photoperiod. The insects were provided regularly with water. Only adult insects, 1 week old or older, were used in the experiments. The heads of the test insects were excised from the live insects and prepared for examination under the scanning electron microscope. Voucher specimens were deposited in Institute of Forest Protection, Jilin Provincial Academy of Forestry, Changchun, China.

\subsection{Scanning electron microscopy (SEM)}

Antennae of specimens were carefully excised from the antennal sockets with fine forceps under a stereomicroscope (Olympus SZX12, Japan). The antennae were first kept in $70 \%$ ethanol for $24 \mathrm{~h}$ and then dehydrated in a graded alcohol series of $75,80,85,90$, and $100 \%$ in each case for $10 \mathrm{~min}$ each. The antennae were individually mounted with dorsal or ventral sides on aluminum stubs with double-sided sticky tapes. Before examination the antennae were sputter-coated with gold $(20 \mathrm{~nm})$ in a Hitachi E-102 high resolution sputter coater. The specimens were examined in a Hitachi S-570 scanning electron microscope (Hitachi, Tokyo, Japan) set at 20kV. 10 antennae of each sex were examined under the SEM.

\subsection{Statistical analysis}

The data were analyzed using the t-test with the statistical program SPSS version 17.0 (SPSS Inc., Chicago, IL) for Windows. 


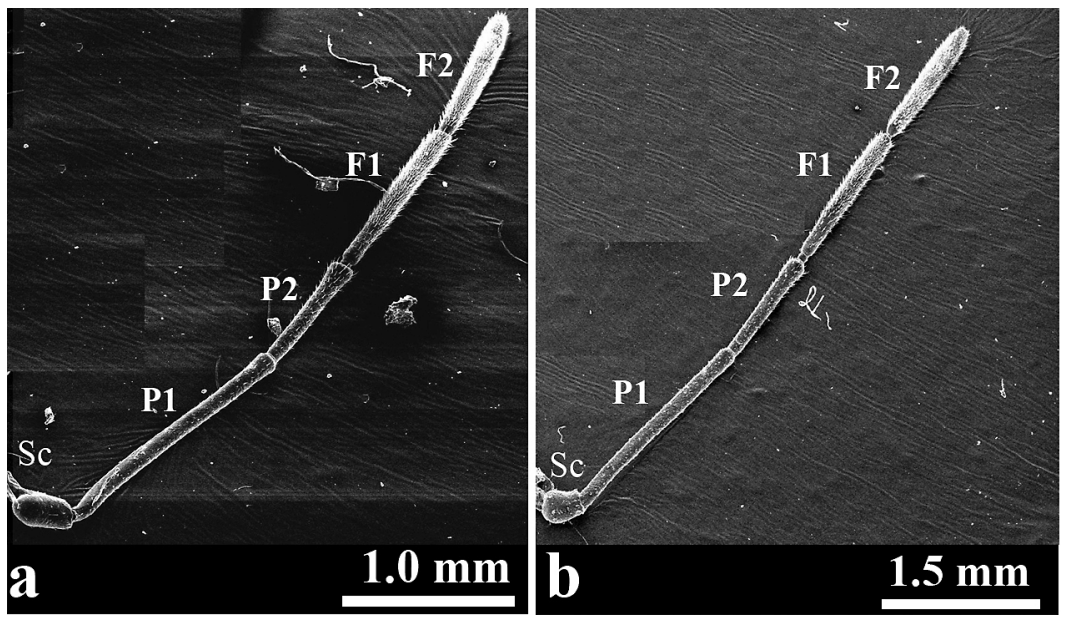

Fig 1. General view of antenna of Arma chinensis showing scape (Sc), segments of pedicel (P1-2) and flagellum (F1-2). - a. Male. - b. Female.

Table 1. Means $( \pm \mathrm{SD})$ of lengths $(\mathrm{mm})$ of antennal segments of Arma chinensis ( $n=10$ per sex).

\begin{tabular}{lcccccc}
\hline Sex & Scape & Pedicel 1 & Pedicel 2 & Flagellum 1 & Flagellum 2 & Total $^{\star}$ \\
\hline Female & $0.402 \pm 0.015$ & $1.772 \pm 0.062$ & $0.730 \pm 0.045$ & $1.158 \pm 0.077$ & $0.946 \pm 0.034$ & $5.008 \pm 0.233$ \\
Male & $0.368 \pm 0.031$ & $1.535 \pm 0.031$ & $0.772 \pm 0.034$ & $1.163 \pm 0.025$ & $1.055 \pm 0.032$ & $4.893 \pm 0.153$
\end{tabular}

* Significant difference between the sexes (Student's t-test, $p<0.05$ ).

Table 2. Means $( \pm \mathrm{SD})$ of lengths and diameters $(\mu \mathrm{m})$ as well as morphological characteristics of different types of antennal sensilla in $A$. chinensis ( $n=10$ per sex).

\begin{tabular}{|c|c|c|c|c|c|c|c|}
\hline \multirow[t]{2}{*}{ Type* } & \multirow[t]{2}{*}{ Sex } & \multirow[t]{2}{*}{ Length** } & \multirow[t]{2}{*}{ Diameter** } & \multicolumn{4}{|c|}{ Morphological characteristics } \\
\hline & & & & Tip & Wall & Shape & Socket \\
\hline \multirow[t]{2}{*}{ ST1 } & Female & $44.60 \pm 1.75$ & $3.31 \pm 0.22$ & Blunt & Smooth & Straight or curved & Wide \\
\hline & Male & $45.46 \pm 2.73$ & $3.02 \pm 0.05$ & & & & \\
\hline \multirow[t]{2}{*}{ ST2 } & Female & $38.70 \pm 1.25$ & $1.91 \pm 0.07$ & Blunt & Smooth & Straight or curved & Wide \\
\hline & Male & $40.66 \pm 2.77$ & $2.13 \pm 0.11$ & & & & \\
\hline \multirow[t]{2}{*}{ SB1 } & Female & $16.96 \pm 2.64$ & $2.55 \pm 0.22$ & Blunt & Smooth & Straight & Tight \\
\hline & Male & $15.45 \pm 4.33$ & $2.28 \pm 0.48$ & & & & \\
\hline \multirow[t]{2}{*}{ SB2 } & Female & $35.48 \pm 11.37$ & $3.35 \pm 0.47$ & Blunt & Smooth & Straight & Tight \\
\hline & Male & $37.23 \pm 4.77$ & $3.88 \pm 0.53$ & & & & \\
\hline \multirow[t]{2}{*}{ SB3 } & Female & $13.17 \pm 3.83$ & $2.29 \pm 0.47$ & Blunt & Grooved & Curved & Tight \\
\hline & Male & $11.3 \pm 2.55$ & $2.14 \pm 0.33$ & & & & \\
\hline \multirow[t]{2}{*}{ SB4 } & Female & $6.87 \pm 2.02$ & $1.73 \pm 0.34$ & Blunt & Smooth & Straight & Tight \\
\hline & Male & $8.41 \pm 1.12$ & $1.69 \pm 0.21$ & & & & \\
\hline \multirow[t]{2}{*}{$\mathrm{SCH}$} & Female & $55.49 \pm 12.01$ & $4.58 \pm 0.43$ & Blunt & Grooved & Straight or curved & Wide \\
\hline & Male & $43.66 \pm 14.86$ & $4.25 \pm 0.90$ & & & & \\
\hline \multirow[t]{2}{*}{ SCA } & Female & - & $1.61 \pm 0.21$ & - & - & - & - \\
\hline & Male & - & $1.55 \pm 0.30$ & - & - & - & - \\
\hline \multirow[t]{2}{*}{ SCO } & Female & $1.20 \pm 0.07$ & $2.38 \pm 0.23$ & - & - & - & - \\
\hline & Male & $1.16 \pm 0.15$ & $2.35 \pm 0.20$ & - & - & - & - \\
\hline
\end{tabular}

* Abbreviations: ST1: Sensilla trichoidea 1; ST2: Sensilla trichoidea 2; SB1: Sensilla basiconica 1; SB2: Sensilla basiconica 2 ; SB3: Sensilla basiconica 3; SB4: Sensilla basiconica 4; SCH: Sensilla chaetica; SCA: Sensilla cavity; SCO: Sensilla coeloconic. ${ }_{* *}$ No significant differences between the sexes (Student's t-test, all $p>0.05$ ). 
Fig 2. Details of antenna of $A$. chinensis. - a. ST1 (sensilla trichoidea 1) on the ventral side of the $1^{\text {st }}$ flagellomere of male. $-b$. The smooth cuticle of ST1 at higher magnification. - c. ST2 (sensilla trichoidea 2) on the ventral side of the $1^{\text {st }}$ flagellomere of male. $-d$. The smooth cuticle of ST2 at higher magnification.
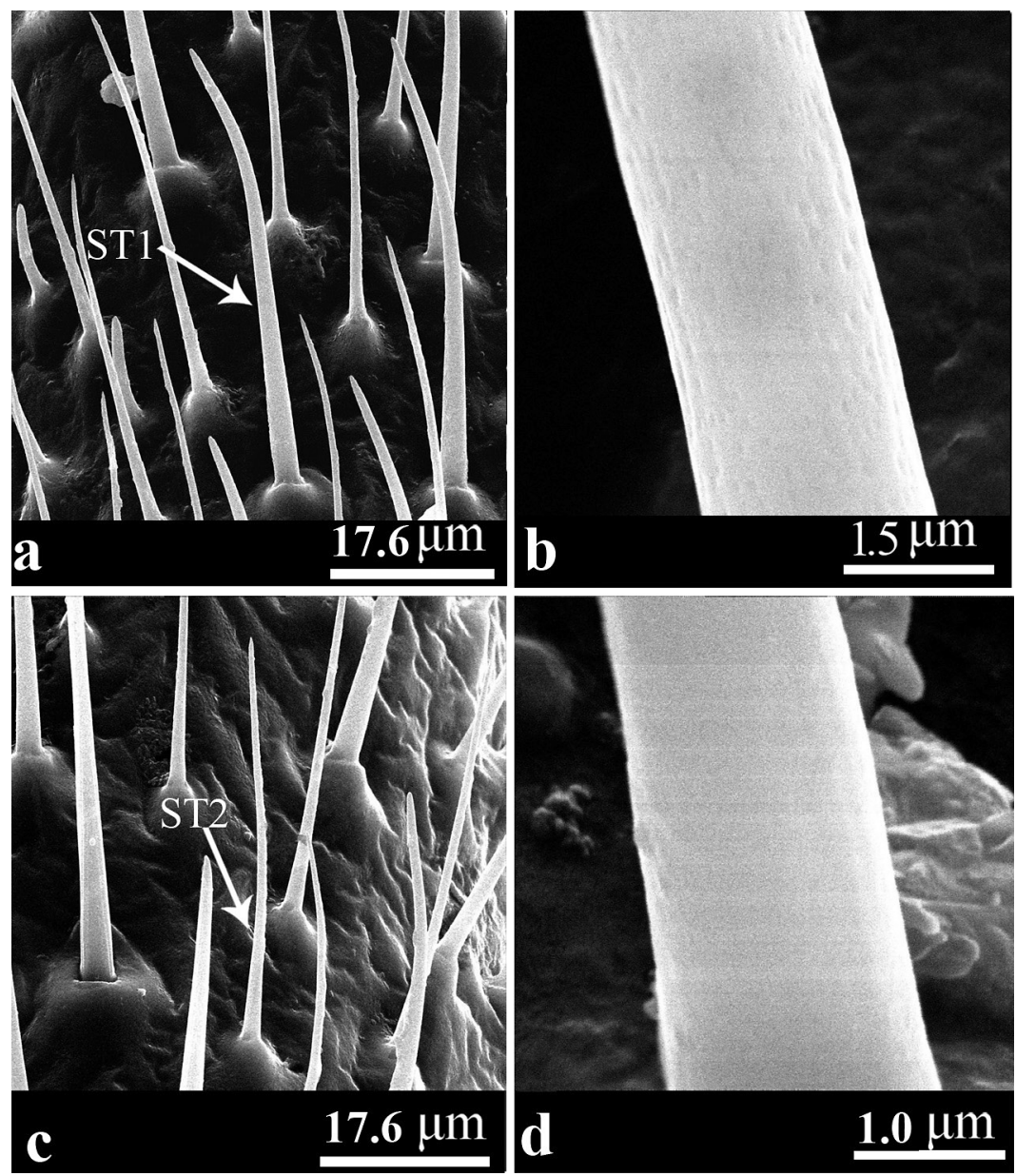

\section{Results}

\subsection{General structure of the antennae}

Antennae of both sexes of $A$. chinensis were morphologically similar. The filiform antennae were comprised of a basal scape (Sc), a two-segmented pedicel (P1, P2) and a two-segmented flagellum (F1, F2) (Fig. 1). Female adults bear much longer antennae than the males. The mean lengths of the antennal segments of $A$. chinensis are summarized in Table 1.

\subsection{Types of sensilla}

Based on their morphology, two types of sensilla trichodea (ST1-2), four types of sensilla basiconica (SB1-4), one type of sensilla chaetica $(\mathrm{SCH})$, one type of sensilla cavity (SCA) and one type of sensilla coeloconica (SCO) were distinguished on the antennae in both sexes. The characteristic morphological features of the antennal sensilla of $A$. chinensis are summarized in Table 2. The type and size of the sensilla covering the different parts of the antenna were similar in the female and male stink bugs, and no sexual dimorphism was found in these sensitive structures (Table 2). The counts of sensilla were made from both the dorsal and ventral sides.

\subsubsection{Sensilla trichodea 1 (ST1)}

ST1 were long, straight or curved hairs, with their bases tightly inserted in an elevation of the cuticle, with a pointed tip (Fig. 2a). The sensilla stood up perpendicularly to the antennal surface and when viewed at a high magnification their wall was smooth with no pores or grooves on the sur- 

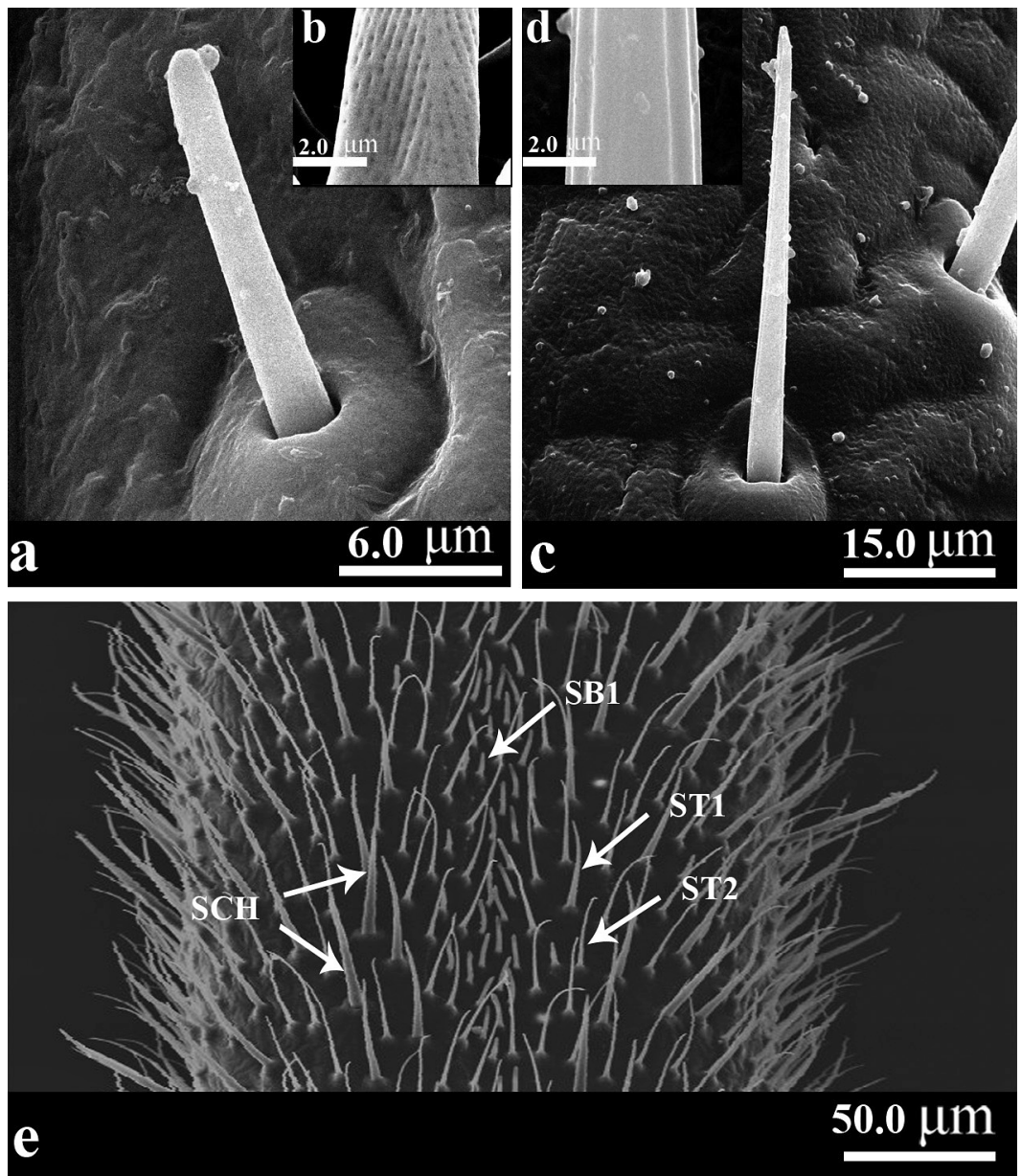

Fig 3. Details of antenna of $A$. chinensis. -a. SB1 (sensilla basiconica 1) on the dorsal side of the $1^{\text {st }}$ pedicel of male. $-b$. Numerous pores on the cuticle of SB1 at higher magnification. - c. SB2 (sensilla basiconica 2) on the ventral side of the $1^{\text {st }}$ flagellomere of female. - d. Longitudinal grooves on the wall of SB2. - e. SB1 on the central axis of the dorsal side of the $2^{\text {nd }}$ flagellomere of female. face (Fig. 2b). They were found scattered on the flagellum of the antennae. ST1 was absent from the scape and the pedicel. This type of sensillum had a mean length and basal diameter $( \pm \mathrm{SD})$ of $44.60 \pm 1.75 \mu \mathrm{m}$ and $3.31 \pm 0.22 \mu \mathrm{m}$ (female) and $45.46 \pm 2.73 \mu \mathrm{m} 3.02 \pm 0.05 \mu \mathrm{m}$ (male), respectively.

\subsubsection{Sensilla trichodea 2 (ST2)}

ST2 were long and slender hairs with straight or slightly curved shafts, and tapering to a sharp point apically (Fig. 2c). The shaft of this sensillum was smooth, arose from an elevated base and did not show any pores (Fig. 2d). They were located only on the flagellum of the antennae. ST2 were on average ( \pm SD) $38.70 \pm 1.25 \mu \mathrm{m}$ (female) and $40.66 \pm 2.77 \mu \mathrm{m}$ (male) in length and $1.91 \pm 0.07 \mu \mathrm{m}$ (female) and $2.13 \pm 0.11 \mu \mathrm{m}$ (male) in basal diameter.

\subsubsection{Sensilla basiconica 1 (SB1)}

SB1 were stout pegs with slightly curved shaft having numerous pores on the walls (Figs. 3a, b). These blunt-tipped sensilla inserted into sockets often formed by slightly elevated craters. These sensilla were found on the central axis of the surface of the terminal antennal segments (Fig. 3e). SB1 measured on average $( \pm$ SD) $16.96 \pm 2.64$ $\mu \mathrm{m}$ (female) and $15.45 \pm 4.33 \mu \mathrm{m}$ (male) in length, $2.55 \pm 0.22$ (female) and $2.28 \pm 0.48 \mu \mathrm{m}$ (male) in basal diameter.

\subsubsection{Sensilla basiconica 2 (SB2)}

SB2 had blunt tips and a well defined socket at the base. They were shorter and thicker at the base than SB1 (Fig. 3c). They were present along the entire length of the antennae of both sexes. But 
Fig 4. Details of antenna of $A$. chinensis. - a. SB3 (Sensilla basiconica 3) on the ventral side of the $2^{\text {nd }}$ pedicel of male. $-b$. Longitudinal grooves on the wall of SB3. - C. A dense group of SB3 on the $2^{\text {nd }}$ pedicel of male. - d. SB4 (sensilla basiconica 4) on the dorsal side of the scape of male. $-\mathrm{e}$. The smooth cuticle of SB4 at higher magnification.
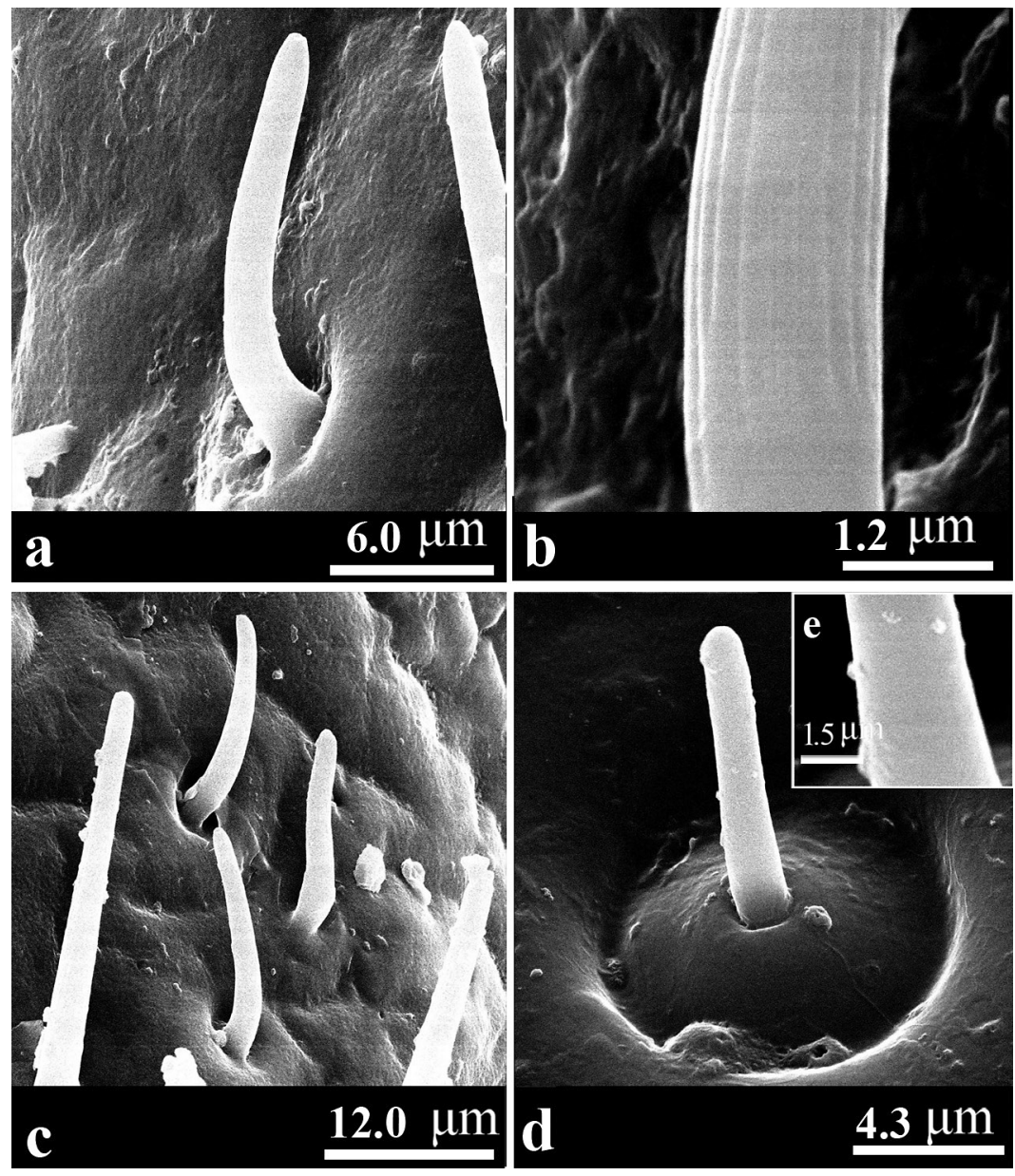

analyzing the SB2 at high magnification we observed some longitudinal grooves on the cuticle (Fig. 3d). They measured on average ( \pm SD) $35.48 \pm 11.37 \mu \mathrm{m}$ (female) and $37.23 \pm 4.77 \mu \mathrm{m}$ (male) in length and $3.35 \pm 0.47$ (female) and 3.88 $\pm 0.53 \mu \mathrm{m}$ (male) in basal diameter.

\subsubsection{Sensilla basiconica 3 (SB3)}

SB3 abruptly curved in the direction of the antennal surface and were on average $( \pm$ SD) $13.17 \pm 3.83 \mu \mathrm{m}$ (female) and $11.3 \pm 2.55 \mu \mathrm{m}$ (male) long pegs with a smooth wall and blunt tip (Figs. 4a, b). Their diameter at the base was 2.29 \pm $0.47 \mu \mathrm{m}$ (female) and $2.14 \pm 0.33 \mu \mathrm{m}$ (male). They were usually situated as a dense group (Fig. 4c) of 3-7 sensilla and there were usually $8.34 \pm$ $3.20 \mu \mathrm{m}$ between separate sensilla.

\subsubsection{Sensilla basiconica 4 (SB4)}

The mean $( \pm \mathrm{SD})$ lengths of SB4 were $6.87 \pm 2.02$ $\mu \mathrm{m}$ (female) and $8.41 \pm 1.12 \mu \mathrm{m}$ (male). They were blunt-tipped pegs with basal diameters of $1.73 \pm 0.34 \mu \mathrm{m}$ (female) and $1.69 \pm 0.21 \mu \mathrm{m}$ (male) and possessed no grooves or pores on the antennal surface (Fig. 4d, e). They were typically inserted into a small dome, bore no articulating socket, and were oriented perpendicularly to the antennal surface. They were situated on the surface of the scape, pedicel, and the first flagellomere.

\subsubsection{Sensilla chaetica (SCH)}

SCH were long sickle-shaped strong bristles with longitudinal grooves accumulating toward the tip, which were located in an open articulating 


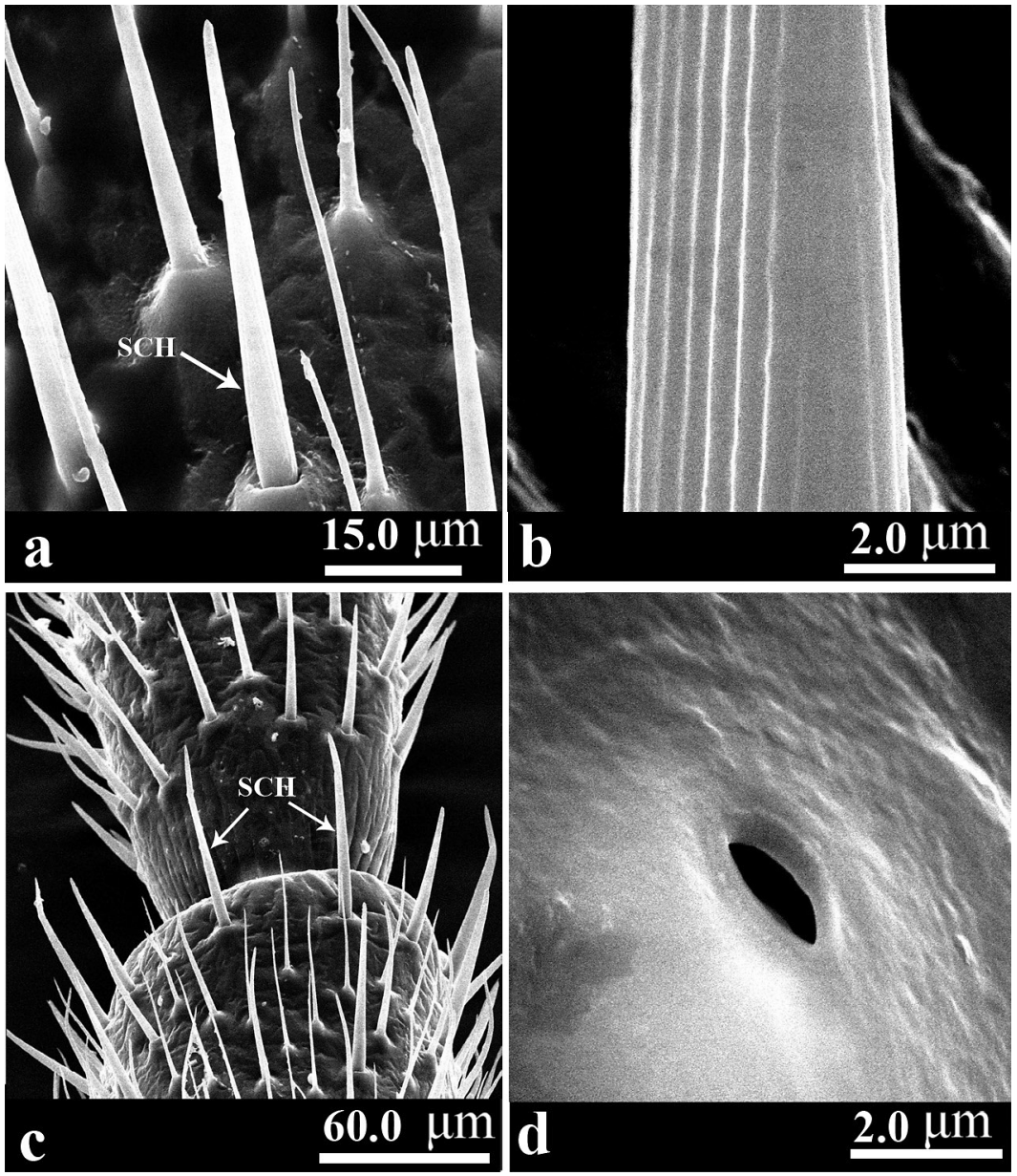

Fig 5. Details of antenna of $A$. chinensis. - a. SCH (sensilla chaetica) on the ventral side of the $2^{\text {nd }}$ flagellomere of female. $-b$. Longitudinal grooves on the wall of $\mathrm{SCH}$. - c. $\mathrm{SCH}$ located on the distal area of the dorsal side of the $1^{\text {st }}$ flagellomere. - d. SCA (Sensilla cavity) on the dorsal side of the $2^{\text {nd }}$ flagellomere of male. socket (Figs. 5a, b). These sensilla lay parallel to the surface and point towards the tip of the antenna. They covered the second pedicel and the two flagellomeres (Fig. 5c). On average ( \pm SD), $\mathrm{SCH}$ measured $55.49 \pm 12.01 \mu \mathrm{m}$ (female) and $43.66 \pm 14.86 \mu \mathrm{m}$ (male) in length and $4.58 \pm 0.43$ $\mu \mathrm{m}$ (female) and $4.25 \pm 0.90 \mu \mathrm{m}$ (male) in basal diameter.

\subsubsection{Sensilla cavity (SCA)}

SCA were single large pores that occurred at the base of the second flagellomere (Fig. 5d). They were on average $( \pm \mathrm{SD}) 1.61 \pm 0.21 \mu \mathrm{m}$ (female) and $1.55 \pm 0.30 \mu \mathrm{m}$ (male) in the diameter. They were situated not only on the dorsal, but also on the ventral side of the second flagellomere. Due to their small numbers these sensilla were not considered in the sensilla counts.

\subsubsection{Sensilla coeloconic (SCO)}

SCO were short peg-like sensory structures sunk into a pit with the apex of the peg not projecting out of the pit (Fig. 6a). They occurred exclusively on the second segment of the flagellum and had a mean $( \pm \mathrm{SD})$ diameter of $2.38 \pm 0.23 \mu \mathrm{m}$ (female) and $2.35 \pm 0.20 \mu \mathrm{m}$ (male). These sensilla were not considered in the sensilla counts because of their limited number.

\subsection{Abundance and distribution of antennal sensilla}

The mean numbers and distribution of sensilla on the segments of $A$. chinensis are recorded in Table 3 . Sensilla were absent on the segmental joint between the second pedicel and the first flagellome- 
Fig 6. Details of antenna of $A$. chinensis. - a. SCO (sensilla coeloconic) on the dorsal side of the $2^{\text {nd }}$ flagellomere of male. - b. Segmental joint of the $2^{\text {nd }}$ pedicel and the $1^{\text {st }}$ flagellomere in male, showing absence of sensilla. - c. Large amount of different types of sensilla on the dorsal side of the $2^{\text {nd }}$ flagellomere of female: SB1: Sensilla basiconica 1, ST1: Sensilla trichoidea 1, SCH:

Sensilla chaetica, ST2: Sensilla trichoidea 2.
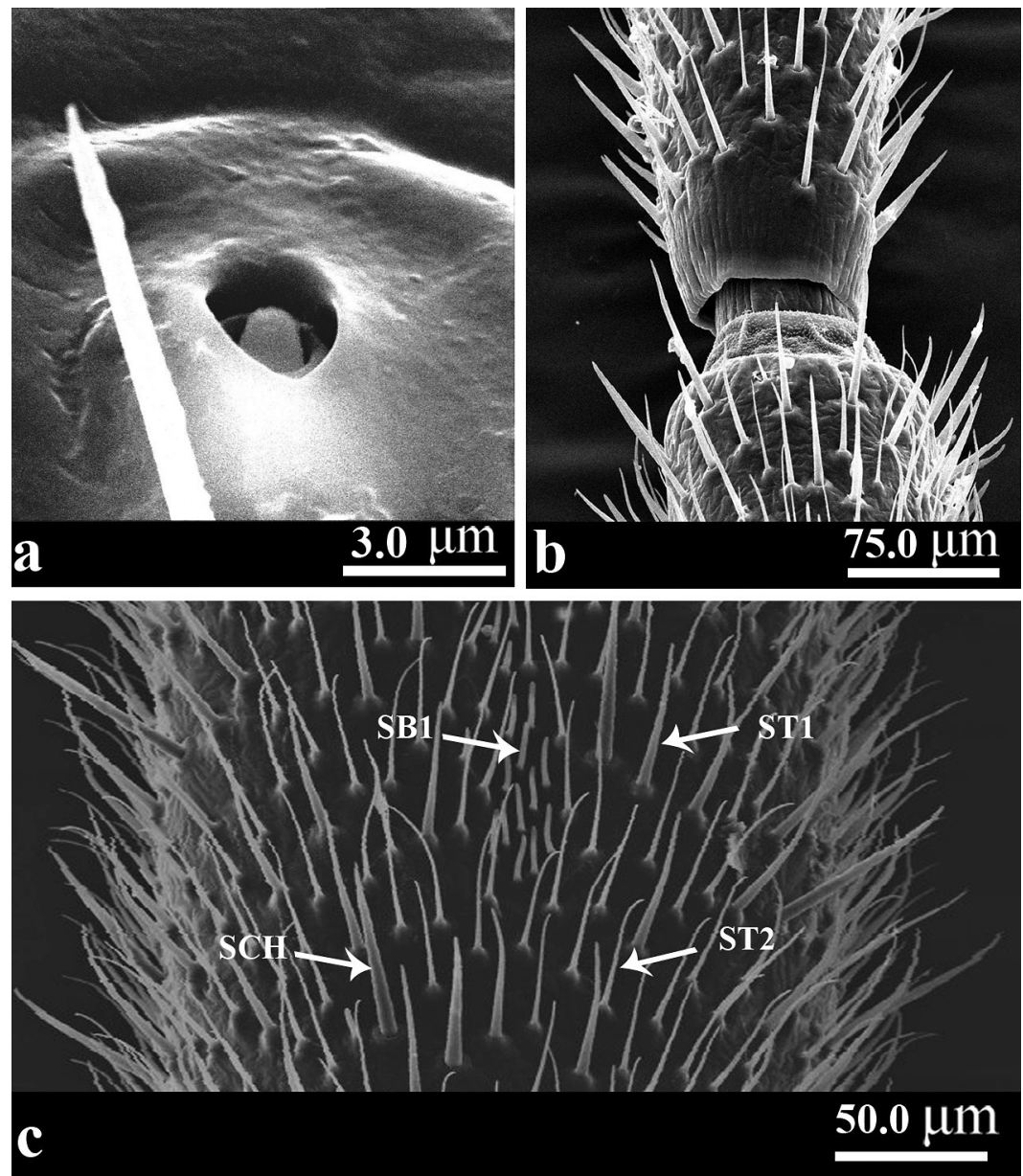

re of both sexes (Fig. 6b). Large amounts of different types of sensilla were distributed on the dorsal and ventral side of the flagellum (Fig. 6c). The distribution patterns of sensilla on the antennae of both sexes of the stink bug were similar. ST1 and ST2 were more abundant than the other types of sensilla on the antennae. SB1 were absent from the scape. SB2 were distributed throughout the antennae. SB3 were distributed on the second segment of the pedicel and the two segments of the flagellum. SB4 were absent from the second flagellum. ST1 and ST2 were absent from the scape and pedicel. SC were located on the second segment of the pedicel and the two segments of the flagellum. SCA and SCO only occurred on the second segment of the flagellum.

\section{Discussion}

The various types of sensilla and their distribution on the antennae of male and female $A$. chinensis as revealed in this study were similar with those reported for other heteropteran insect species (Rani \& Madhavendra 1995, Catalá, 1997, Onagbola et al. 2008). The antennae of insects have been typically described as consisting of the three usual components: scape, pedicel, and flagellum (Chapman 1998). The flagellum of A. chinensis is formed of two segments that hold the largest number of sensilla among the different segments of the antenna. Similarly, two segments were observed in Neomegalotomus parvus (Westwood) (Ventura \& Panizzi 2005) (Alydidae), Panstrongylus megistus (Burmeister) (Villela et al. 2005) and Rhodnius prolixus (Stal) (Akent'eva 2008) (Reduviidae), Coreus margi- 
Table 3. Mean numbers per segment $( \pm S D)$ and distribution of different types of antennal sensilla of female and male $A$. chinensis ( $n=5$ antennae per sex). For abbreviations, see Table 2.

\begin{tabular}{|c|c|c|c|c|c|c|c|}
\hline Type & Sex & Scape & Pedicel 1 & Pedicel 2 & Flagellum 1 & Flagellum 2 & Total \\
\hline \multirow[t]{2}{*}{ ST1 ${ }^{\text {ns }}$} & Female & 0 & 0 & 0 & $242.0 \pm 21.5$ & $270.0 \pm 19.5$ & $542.3 \pm 44.0$ \\
\hline & Male & 0 & 0 & 0 & $193.3 \pm 10.5$ & $420.0 \pm 30.4$ & $613.3 \pm 40.9$ \\
\hline \multirow[t]{2}{*}{$\mathrm{ST} 2^{\mathrm{ns}}$} & Female & 0 & 0 & 0 & $493.6 \pm 20.5$ & $521.6 \pm 19.8$ & $1015.3 \pm 40.3$ \\
\hline & Male & 0 & 0 & 0 & $317.6 \pm 21.1$ & $611.3 \pm 25.4$ & $928.9 \pm 46.5$ \\
\hline \multirow[t]{2}{*}{$\mathrm{SB} 1^{\mathrm{ns}}$} & Female & 0 & $110.6 \pm 11.1$ & $63.3 \pm 6.0$ & $20.6 \pm 2.5$ & $127.6 \pm 12.5$ & $322.3 \pm 32.1$ \\
\hline & Male & 0 & $114.3 \pm 11.0$ & $26.0 \pm 6.0$ & $58.6 \pm 17.0$ & $148.6 \pm 12.1$ & $347.6 \pm 46.1$ \\
\hline \multirow[t]{2}{*}{$\mathrm{SB}^{\mathrm{ns}}$} & Female & $6.0 \pm 0$ & $65.0 \pm 8.0$ & $96.6 \pm 8.7$ & $306.3 \pm 19.2$ & $124.3 \pm 5.1$ & $598.3 \pm 41.1$ \\
\hline & Male & $5.0 \pm 0$ & $41.0 \pm 7.2$ & $99.0 \pm 5.5$ & $186.6 \pm 10.7$ & $144.0 \pm 5.5$ & $475.6 \pm 29.1$ \\
\hline \multirow[t]{2}{*}{ SB3* } & Female & 0 & 0 & $7.0 \pm 2.0$ & $26.6 \pm 1.5$ & $8.3 \pm 1.5$ & $41.9 \pm 5.0$ \\
\hline & Male & 0 & 0 & $8.3 \pm 2.5$ & $19.6 \pm 1.5$ & $45.0 \pm 11.1$ & $72.9 \pm 15.1$ \\
\hline \multirow[t]{2}{*}{ SB4 ${ }^{\text {ns }}$} & Female & $30.3 \pm 3.0$ & $81.0 \pm 4.0$ & $23.6 \pm 2.1$ & $15.6 \pm 3.1$ & 0 & $120.3 \pm 9.1$ \\
\hline & Male & $31.6 \pm 3.1$ & $59.3 \pm 13.2$ & $6.0 \pm 0$ & $35.6 \pm 4.0$ & 0 & $132.6 \pm 20.2$ \\
\hline \multirow[t]{2}{*}{$\mathrm{SCH}^{*}$} & Female & 0 & 0 & $16.0 \pm 3.0$ & $49.3 \pm 8.1$ & $75.6 \pm 13.0$ & $140.9 \pm 24.0$ \\
\hline & Male & 0 & 0 & $12.6 \pm 2.5$ & $108.3 \pm 11.0$ & $92.6 \pm 6.5$ & $213.6 \pm 20.0$ \\
\hline
\end{tabular}

* Significant difference in total number of antennal sensilla between the sexes (Student's t-test, $p<0.05$ ).

$n s=$ No significant difference in total number of antennal sensilla between the sexes (Student's t-test, $p>0.05$ ).

natus (Linnaeus) (Akent'eva 2008) and Leptoglossus zonatus (Dallas) (Gonzaga-Segura et al. 2013) (Coreidae), and Nezara viridula (Linnaeus) (Brézot et al. 1997) (Pentatomidae). Gonzaga-Segura et al. (2013) inferred that this could be an adaptation to improve olfaction. Our study revealed nine morphologically different types of sensilla on the antennae of both sexes of $A$. chinensis, similar to those described for other stink bugs (Brézot et al. 1997, Chinta et al. 1997, Rani \& Madhavendra 2005, Silva et al. 2010). The presence of sensilla campaniform and sensilla placoid found on other heteropteran insects (Gonzaga-Segura et al. 2013) were not found on $A$. chinensis.

Sensilla trichodea 1 (ST1) resemble the "type 5 sensilla" in the green stink bug, $N$. viridula (Brézot et al. 1997); "long straight hair type 4" in the tarnished plant bug, Lygus lineolaris (Palisot de Beauvois) (Chinta et al. 1997); "thick-walled trichoid sensilla" in the $P$. megistus (Catalá, 1997); "aporous sensilla trichodea type II" in the Asian citrus psyllid, Diaphorina citri Kuwayama (Onagbola et al. 2008); "trichoid sensilla 1" in Euschistus heros (Fabricius), Piezodorus guildinii (Westwood) and Edessa meditabunda (Fabricius) (Silva et al. 2010). Sensilla trichodea 2 (ST2) with blunt tip in A. chinensis appear to be identical with the "sensilla trichoidea type I" in Odontopus nigricornis (Stall) (Rani \& Madha- vendra 1995); "type I sensilla" in the green stink bug, N. viridula (Brézot et al. 1997) and "thinwalled trichoid sensilla" in the $P$. megistus (Catalá 1997). They are the most abundant type of sensilla present on the antennae of these and many other stink bugs. Shorter or longer blunttipped hairs, which do not articulate at their base, like the sensilla trichodea (ST) in A. chinensis, occur abundantly on the antennae of many wasps, beetles and moths (Bleeker et al. 2004, Merivee et al. 1999, Lopes et al. 2005, Castrejón Gómez \& Carrasco 2008). Sensilla trichodea have traditionally been thought of as the contact chemoreceptors (Schneider 1964). In N. viridula, they have been reported to be good candidates for contact chemoreception based on their external structure (Brézot et al. 1997). Bioassay experiments of the mating behavior on Phoracantha semipunctata (Fabricius) demonstrated that sensilla trichodea served as a contact chemoreceptor (Lopes et al. 2005). Because accounting for more than $50 \%$ of the total number of the antennal sensilla, sensilla trichodea can be considered the main sensory receptors involved in the chemical sense in neotropical bugs (Silva et al. 2010). ST was the most abundant of all sensillum types on the antennae of both sexes of $A$. chinensis, and they were also thought to function as chemoreceptors (Zacharuk 1985).

Large articulated bristles with blunt tip, $\mathrm{SCH}$ 
in A. chinensis, seem to be identical with the"bristle-like type3" in N. viridula (Brézot et al. 1997), "long curved bristle type 2" in L. lineolaris (Chinta et al. 1997). Brézot et al. (1997) suggested that the flexible socketed base, the length of the hair, the dendrite not protruding in the hair, the presence of a cuticular shaft under the cuticle near the base of this type of sensillum are characteristics generally correlated with mechanoreception in $N$. viridula. In L. lineolaris, the presence of a thick cuticle and a single terminal pore of this type of sensillum indicated its possible involvement in chemoreception in contacts (Chinta et al. 1997). In Monochamus notatus (Drury) and M. scutellatus (Say), they can be considered as the receptors responding to sound, wind, or touch (Dyer \& Seabrook 1975). The absence of pores in this sensilla precludes a chemosensory role in $A$. chinensis (Fig. 5b). SCH lacked pores and protruded above all other sensilla, so we assume that they function as mechanoreceptor in $A$. chinensis.

Sensilla basiconica 1 (SB1) with multiple pores and without flexible sockets of $A$. chinensis look like the "sensilla basiconica type I" in the stink bug $O$. nigricornis (Rani \& Madhavendra 1995); "type 4 sensilla" in the green stink bug, $N$. viridula (Brézot et al. 1997); "short peg" in the tarnished plant bug, L. lineolaris (Chinta et al. 1997); "sensilla basiconica type 1 " in the ground beetle, Bembidion properans Stephens (Merivee et al. 2002); "basiconic sensilla type 3" in E. heros, $P$. guildinii and E. meditabunda (Silva et al. 2010). SB1 should correspond to the "thinwalled" (Slifer 1970), "single-walled, wall pore sensilla" (Altner \& Prillinger 1980) and "multiporous chemosensilla" (Zacharuk 1980). Sensilla basiconica bear structural features such as a nonflexible base, a thin, multiporous cuticular wall, a pore-tubule system and branched dendritic segments (Zacharuk 1980). The numerous pores and branched dendrites are traditionally considered to provide evidence that these sensilla basiconica function as olfactory receptors (Altner \& Prillinger 1980, Zacharuk 1985). The cuticular wall of SB1 bears numerous pores in A. chinensis (Fig. $2 \mathrm{~b}$ ). Based on the ultrastructure observed by SEM, SB1s are inferred as the olfactory receptors in A. chinensis. Sexual dimorphism in the numbers of these sensilla was observed in L. lineolaris (Chinta et al. 1997). In the species studied here the number of SB1 was approximately equal between the males and the females (Table 3). In other insects, these basiconic sensilla are known to be olfactory receptors responding to food and habitat related compounds (Schneider 1964, Zacharuk 1985).

The clusters of SB1 are located on the distal part of the second flagellomere (Fig. 3e). Clusters of olfactory sensilla basiconica have been identified also in many coleopteran species, such as $M$. notatus and M. scutellatus (Dyer \& Seabrook 1975), Hypera meles (Fabricius) (Smith et al. 1976), Psacothea hilaris (Pascoe) (Dai \& Honda 1990), Phyllotera cruciferae (Goeze), Psylliodes punctulata Melsheimer, Epitrix cucumeris (Harris) and Psylliodes affinis (Paykull) (Ritcey \& McIver 1990), and Geotrupes auratus Motschulsky and Copris pecuarius Lewis (Inouchi et al. 1987). It has been inferred that such olfactory sensilla clusters function as sensory fields (Dyer $\&$ Seabrook 1975) and may compose an enlarged odor-sensing area that wound be advantageous for long-distance olfactory detection (Inouchi et al. 1987).

Sensilla basiconica 2 (SB2) of $A$. chinensis are common on the antennae of many stink bugs. These sensilla resemble the "type 2 sensilla" of N. viridula (Brézot et al. 1997), "basiconic sensilla" of Riptortus pedestris Fabricius, Elasmolomus sordidus (Fabricius), Cyclopelta siccifolia Westwood and Chrysocoris purpurea (Westwood) (Rani \& Madhavendra 2005), and "basiconic sensilla 2" of E. heros, P. guildinii and E. meditabunda (Silva et al. 2010). Silva et al. (2010) suggested that this type of sensillum may be related to finding food or suitable habitats. Some authors have assigned a thermo- or chemoreception function to these sensilla (Chapman 1982, Zacharuk 1985).

Sensilla basiconica 3 (SB3) of A chinensis are very similar to the "sensilla basiconica type 1" of the ground beetle Platynus dorsalis (Pontoppidan) (Merivee et al. 2001) and "sensilla basiconica type 2" in the ground beetle, B. properans (Merivee et al. 2002). Non-articulated blunt-tipped basiconic sensilla are common on the antennal flagellum of most insects. In the ground beetle Nebria brevicollis (Fabricius) and the cigarette beetle Lasioderma serricorne (Fabricius), it was demonstrated that the wall of 
these sensilla is perforated by numerous tiny pores (Daly \& Ryan 1979, Okada et al. 1992). The numerous pores and branched dendrites are considered to be evidence that these basiconic sensilla function as olfactory receptors (Altner \& Prillinger 1980, Zacharuk 1985). In this study, we did not detect pores in the cuticle of SB3 (Fig. 4b). Single cell recording studies and behavioral experiments are needed to confirm their function.

The appearance and small number of sensilla basiconica 4 (SB4) of $A$. chinensis are similar with "sensilla basiconica type VII" in the click beetle, Agriotes obscurus Linnaeus (Merivee 1992), "sensillum styloconicum" in the cigarette beetle L. serricorne (Okada et al. 1992), "doublewalled sensilla" in Ips typographus (Linnaeus) (Hallberg 1982), "sensilla basiconica II" in the ladybird beetle Semiadalia undecimnotata Schneider (Jourdan et al. 1995). Sensilla without pores are either mechanosensitive or thermo/hygrosensitive in A. chinensis (Altner \& Prillinger 1980, Keil 1999).

Sensilla cavity (SCA) in A. chinensis are similar to those of "cavity sensillum" of eight Acrididae species (Li et al. 2007), "sensilla coeloconica" of B. properans (Merivee et al. 2002), "sensilla cavity" of Callosobruchus chinensis (Linnaeus) and C. maculatus (Fabricius) (Hu et al. 2009), "sensilla cavity" of Cnaphalocrocis medinalis (Guenée) (Sun et al. 2011) and probably in other heteropteran species as well. Chemo-, thermo-, or hygroreception is the most probable function for these sensilla (Zacharuk 1985). They were inferred to function as contact-chemoreceptors, allowing the insect to obtain information on the suitability of any plant they touch (Sun et al. 2011).

Sensilla coeloconica (SCO) were found only on the second segment of the flagellum of $A$. chinensis. Sensilla with similar morphological features were found on the flagellum of $N$. viridula, $C$. purpurea (West), E. heros, P. guildinii and L. zonatus (Brézot et al. 1997, Rani \& Madhavendra 2005, Silva et al. 2010, Gonzaga-Segura et al. 2013) and Reduviidae (Catalá 1997). In social insects, such as ants and wasps, whose behavior is guided by variations in temperature, sensilla coeloconica are chemoreceptors that respond to air temperature changes (Ruchty et al. 2009). In lepidopterans these sensilla are olfactory receptors, possibly sensitive to volatile plant odors (Van der Pers 1981, Pophof 1997), and in homopterans they function as hygroreceptors preventing desiccation of the antennae (Kristoffersen et al. 2006).

Further studies on functional antennal morphology and anatomy are needed to confirm the proposed functions of the sensilla identified in this study. The present results provide necessary background information for our ongoing study on electrophysiology and chemical ecology of $A$. chinensis.

Acknowledgements. We thank two anonymous reviewers for valuable suggestions on the manuscript. This work was supported by "Twelfth Five-year" Plan for the National Science and Technology Support Program of China (grant 2012BAD19B0705), Special Fund for Forest Scientific Research in the Public Welfare of China (grant 201404413) and Jilin Province Science and Technology Development Plan Item of China (grant 20122126). We thank our colleagues for their assistance in specimen collection and rearing of the insects.

\section{References}

Akent'eva, N. A. 2008: The formation of the antenna sensory apparatus in some bug (Heteroptera) species in the course of their postembryonic development. Entomological Review 88: 381-390.

Altner, H. \& Prillinger, L. 1980: Ultrastructure of invertebrate chemo-, thermo-, and hygroreceptors and its functional significance. - International Review of Cytology 67: 69-139.

Bleeker, M. A. K., Smid, H. M., van Aels, A. C., van Loon J. J. A. \& Vet L. M. E. 2004: Antennal sensilla of two parasitoid wasps: A comparative scanning electron microscopy study. - Microscopy Research and Technique 63: 266-273.

Bourdais, D., Vernon, P., Krespi, L., Lannic, J. L. \& Van Baaren, J. 2006: Antennal structure of male and female Aphidius rhopalosiphi DeStefani-Peres (Hymenoptera: Braconidae): Description and morphological alterations after cold storage or heat exposure. - Microscopy Research and Technique 69: 1005-1013.

Brézot, P., Tauban, D. \& Renou, M. 1997: Sense organs on the antennal flagellum of the green stink bug, Nezara viridula (L.) (Heteroptera: Pentatomidae): sensillum types and numerical growth during the post-embryonic development. - International Journal of Insect Morphology and Embryology 25: 427-441.

Castrejón Gómez, V. R. \& Carrasco, J. V. 2008: Morphological characteristics of Antennal Sensilla in Talponia batesi (Lepidoptera: Tortricidae). - Annals of the Entomological Society of America 101: 181-188.

Catalá, S. S. 1997: Antennal sensilla of Triatominae (Hemiptera: Reduviidae): a comparative study of five gen- 
era. - International Journal of Insect Morphology and Embryology 26: 67-73.

Chapman, R. F. 1982: Chemoreception: The significance of receptor numbers. - Advances in Insect Physiology 16: 247-356.

Chapman, R. F. 1998: The insects: Structure and function. $4^{\text {th }}$ Edition. - Cambridge University Press, New York. 788 pp.

Chinta, S., Dickens, J. C. \& Baker, G. T. 1997: Morphology and distribution of antennal sensilla of the tarnished plant bug, Lygus lineolaris (Palisot de Beauvois) (Hemiptera: Miridae). - International Journal of Insect Morphology and Embryology 26: 21-26.

Cônsoli, F. L., Kitajima, E. W. \& Postali Parra, J. R. 1999: Sensilla on the antenna and ovipositor of the parasitic wasps Trichogramma galloi Zucchi and T. pretiosum Riley (Hymenoptera: Trichogrammatidae). - Microscopy Research and Technique 45: 313-324.

Dai, H. \& Honda, H. 1990: Sensilla on the antennal flagellum of the yellow spotted longicorn beetle, Psacothea hilaris (Pascoe) (Coleoptera: Cerambycidae). Applied Entomology and Zoology 25: 273-295.

Daly, P. J. \& Ryan, M. F. 1979: Ultrastructure of antennal sensilla of Nebria brevicollis (Fab.) (Coleoptera: Carabidae). - International Journal of Insect Morphology and Embryology 8: 169-181.

De Bortoli, S. A., Otuka, A. K., Vacari, A. M., Martins, M. I. E. G. \& Volpe, H. X. L. 2011: Comparative biology and production costs of Podisus nigrispinus (Hemiptera: Pentatomidae) when fed different types of prey. — Biological Control 58: 165-174.

Dyer, L. J. \& Seabrook, W. D. 1975: Sensilla on the antennal flagellum of the Sawyer Beetles Monochamus notatus (Drury) and Monochamus scutellatus (Say) (Coleoptera: Cerambycidae). - Journal of Morphology 146: 513-532.

Gonzaga-Segura, J., Carrasco, J. V. \& Castrejón Gómez, V. R. 2013: Sense Organs on the Antennal Flagellum of Leptoglossus zonatus (Heteroptera: Coreidae). - Annals of the Entomological Society of America 106: 511-517.

Hallberg, E. 1982: Sensory organs in Ips typographus (Insecta: Coleoptera) fine structure of antennal sensilla. — Protoplasma 111: 206-214.

Helmey-Hartman, W. L. \& Miller, C. W. 2014: ContextDependent Mating Success in Murgantia histrionica (Hemiptera: Pentatomidae). - Annals of the Entomological Society of America 107: 264-273.

Hu, F., Zhang, G. N. \& Wang, J. J. 2009: Scanning electron microscopy studies of antennal sensilla of bruchid beetles, Callosobruchus chinensis (L.) and Callosobruchus maculatus (F.) (Coleoptera: Bruchidae). - Micron 40: 320-326.

Inouchi, J., Shibuya, T., Matsuzaki, O. \& Hatanaka, T. 1987: Distribution and fine structure of antennal olfactory sensilla in Japanese dung beetles, Geotrupes auratus Mtos. (Coleoptera: Geotrupidae) and Copris pecuarius Lew. (Coleoptera: Scarabaeidae). - International Journal of Insect Morphology and Embryology 16: $177-187$.
Jourdan, H., Barbier, R., Bernard, J. \& Ferran, A. 1995: Antennal sensilla and sexual dimorphism of the adult ladybird beetle Semiadalia undecimnotata Schn. (Coleoptera: Coccinellidae). - International Journal of Insect Morphology and Embryology 24: 307-322.

Keil, T. A. 1999: Morphology and development of the peripheral olfactory organs. - In: Hansson, B. S. (ed.), Insect olfaction: 5-47. Springer Press, Heidelberg. $467 \mathrm{pp}$.

Keil, T. A. \& Steinbrecht, R. A. 1984: Mechanoreceptive and olfactory sensilla in insects. - In: King, R. C. \& Akai, H. (eds.), Insect ultrastructure: 477-516. Plenum, New York. 636 pp.

Kristoffersen, L., Hallberg, E., Wallén, R. \& Anderbrant, O. 2006: Sparse sensilla array on Trioza apicalis (Homoptera: Triozidae) antennae — an adaptation to high stimulus level. - Arthropod Structure and Development 35: 85-92.

Li, N., Ren, B. Z. \& Liu, M. 2007: The study on antennal sensilla of eight Acrididae species (Orthoptera: Acridoidea) in Northeast China. —Zootaxa 1544: 59-68.

Lopes, O., Marques, P. C. \& Araujo, J. 2005: The role of antennae in mate recognition in Phoracantha semipunctata (Coleoptera: Cerambycidae). - Journal of Insect Behavior 18: 243-257.

Merivee, E. 1992: Antennal sensilla of the female and male elaterid beetle Agriotes obscurus L. (Coleoptera: Elateridae). - Proceedings of the Estonian Academy of Sciences 41: 189-215.

Merivee, E., Rahi, M. \& Luik, A. 1999: Antennal sensilla of the click beetle, Melanotus villosus (Geoffroy) (Coleoptera: Elateridae). - International Journal of Insect Morphology and Embryology 28: 41-51.

Merivee, E., Ploomi, A., Rahi, M., Luik, A. \& Sammelselg, V. 2001: Antennal sensilla of the ground beetle Platynus dorsalis (Pontoppidan, 1763) (Coleoptera: Carabidae). - Microscopy Research and Technique 55: 339-349.

Merivee, E., Ploomi, A., Rahi, M., Bresciani, J., Ravn, H. P., Luik, A. \& Sammelselg, V. 2002: Antennal sensilla of the ground beetle Bembidion properans Steph. (Coleoptera: Carabidae). — Micron 33: 429-440.

Okada, K., Mori, M., Shimazaki, K. \& Chuman, T. 1992: Morphological studies on the antennal sensilla of the cigarette beetle, Lasioderma serricorne (F.) (Coleoptera: Anobiidae). - Applied Entomology and Zoology 27: 269-276.

Onagbola, E. O., Meyer, W. L., Boina, D. R. \& Stelinski, L. L. 2008: Morphological characterization of the antennal sensilla of the Asian citrus psyllid, Diaphorina $\mathrm{ci}$ tri Kuwayama (Hemiptera: Psyllidae), with reference to their probable functions. - Micron 39: 1184-1191.

Pophof, B. 1997: Olfactory responses recorded from sensilla coeloconica of the silkmoth Bombyx mori. Physiological Entomology 22: 239-248.

Rani, P. U. \& Madhavendra, S. S. 1995: Morphology and distribution of antennal sense organs and diversity of mouthpart structures in Odontopus nigricornis (Stall) and Nezara viridula L. (Hemiptera). - International 
Journal of Insect Morphology and Embryology 24: 119-132.

Rani, P. U. \& Madhavendra, S. S. 2005: External morphology of antennal and rostral sensillae in four hemipteran insects and their possible role in host plant selection. - International Journal of Tropical Insect Science 25: 198-207.

Ritcey, G. M. \& McIver, S. 1990: External morphology of antennal sensilla of four species of adult flea beetles (Coleoptera: Chrysomelidae: Alticinae). — International Journal of Insect Morphology and Embryology 19: 141-153.

Ruchty, M., Romani, R., Kuebler, L.S., Ruschioni, S., Roces, F., Isidoro, N. \& Kleineidam, C. J. 2009: The thermo-sensitive sensilla coeloconica of leaf-cutting ants (Atta vollenweideri). - Arthropod Structure and Development 38: 195-205.

Schneider, D. 1964: Insect antennae. - Annual Review of Entomology 9: 103-122.

Silva, C. C., de Capdeville, G., Moraes, M. C., Falcão, R., Solino, L. F., Laumann, R. A., Silva, J. P. \& Borges, M. 2010: Morphology, distribution and abundance of antennal sensilla in three stink bug species (Hemiptera: Pentatomidae). - Micron 41: 289-300.

Slifer, E. H. 1970: The structure of arthropod chemoreceptors. - Annual Review of Entomology 15: 121-142.

Smith, C. M., Frazier, J. L., Coons, L. B. \& Knight, W. E. 1976: Antennal sensilla of the clover head weevil $\mathrm{Hy}$ pera Meles (F.) (Coleoptera: Curculionidae). - International Journal of Insect Morphology and Embryology 5: 349-355.

Song, L. W., Tao, W. Q., Guan, L., Li, X. P. \& Chen, Y. Q. 2010: Influence of host plants and rearing density on growth, development and fecundity of Arma chinensis. - Scientia Silvae Sinicae 46: 105-110.

Städler, E. 1984: Contact chemoreception. — In Bell, W. J. \& Cardé, R. T. (eds.), Chemical ecology of insects: 33-35. Chapman \& Hall Press, London. 450 pp.

Streams, F. A. \& Pimentel, D. 1963: Studies on the sex ratio of the harlequin bug, Murgantia histrionic (Hemiptera: Pentatomidae). - Annals of the Entomological Society of America 56: 712-716.

Sun, X., Wang, M. Q. \& Zhang, G. A. 2011: Ultrastructural Observations on Antennal Sensilla of Cnaphalocrocis medinalis (Lepidoptera: Pyralidae). - Microscopy Research and Technique 74:113-121.
Van der Pers, J. N. C. 1981: Comparison of electroantennogram response spectra to plant volatiles in seven species of Yponomeutidae and in the tortricidae Adoxophyes orana. - Entomologia Experimentalis et Applicata 30: 181-192.

Ventura, M. U. \& Panizzi, A. R. 2005: Morphology of olfactory sensilla and its role in host plant recognition by Neomegalotomus parvus (Westwood) (Heteroptera: Alydidae). - Brazilian Archives of Biology and Technology 48: 589-597.

Villela, M. M., Catalá, S., Juberg, J., Silva, I. G. \& Dias, J. C. P. 2005: Patterns of antenal sensilla of Panstrongylus megistus from three Brazilian states. - Memórias do Instituto Oswaldo Cruz 100: 699-702.

Xu, C. H., Yan, J. J. \& Yao, D. F. 1984: The relation between the development of Arma chinensis and temperature. - Scientia Silvae Sinicae 20: 96-99.

Xu, C. H., Yao, D. F., Li, Y. M. \& Yan, J. J. 1981: A preliminary study of predatory natural enemy, Arma chinensis Fallou. — Practical Forestry Technology 4: 24-27

Yu, Q. Q., Liu, Z. K., Chen, C. \& Wen, J. B. 2013: Antennal Sensilla of Eucryptorrhynchus chinensis (Olivier) and Eucryptorrhynchus brandti (Harold) (Coleoptera: Curculionidae). - Microscopy Research and Technique 76: 968-978.

Zacharuk, R. Y. 1980: Ultrastructure and function of insect chemosensilla. - Annual Review of Entomology 25: 27-47.

Zacharuk, R. Y. 1985: Antennae and sensilla. - In: Kerkut, G. A. \& Gilbert, L. I. (eds.), Comprehensive insect physiology, biochemistry and pharmacology: 1-69. Pergamon Press, Oxford. 8356 pp.

Zahn, D. K., Girling, R. D., McElfresh, J. S., Cardé, R. T. \& Millar, J. G. 2008: Biology and reproductive behavior of Murgantia histrionica (Heteroptera: Pentatomidae). - Annals of the Entomological Society of America 101: 215-228.

Zou, D. Y., Coudron, T. A., Liu, C. X., Zhang, L. S., Wang, M. Q. \& Chen, H. Y. 2013: Nutrigenomics in Arma chinensis: transcriptome analysis of Arma chinensis fed on artificial diet and chinese oak silk moth Antheraea pernyi pupae. - PLoS ONE 8: e60881.

Zou, D. Y., Wang, M. Q., Zhang, L. S., Zhang, Y., Zhang, X. J. \& Chen, H. Y. 2012: Taxonomic and bionomic notes on Arma chinensis (Fallou) (Hemiptera: Pentatomidae: Asopinae). — Zootaxa 3382: 41-52. 